\title{
A new method of surgical treatment for recurrent labial adhesions in a pre-pubertal girl
}

\author{
D Silva', G K C Jayalath², A K P Ranaweera², M Jayawardane, M D A Sudeshika'
}

Ceylon Medical Journal 2012; 57: 168-169

\section{Introduction}

Labial fusion is a common paediatric gynecological problem and occurs more frequently between 3 months and 3 years [1]. Treatment options available are medical and surgical [2]. Recurrence is a common problem after both modalities of treatment [3]. We report a technique to prevent recurrent labial adhesions until epithelialisation occurs.

\section{Case report}

A pre-pubertal eleven year old girl was referred to the gynaecology clinic with recurrent labial adhesions. Due to the recurrence of urinary tract infections aggravated by the labial adhesions she was treated four times with conventional surgical separation followed by local application of oestrogen cream over a period of 3 years.

On examination she had densely fused labia minora extending anteriorly from posterior fourchette and partially occluding the introitus (Figure 1). The following new surgical technique was used to treat her. She was prescribed oestrogen cream for local application. During the follow up of two years there was no recurrence.

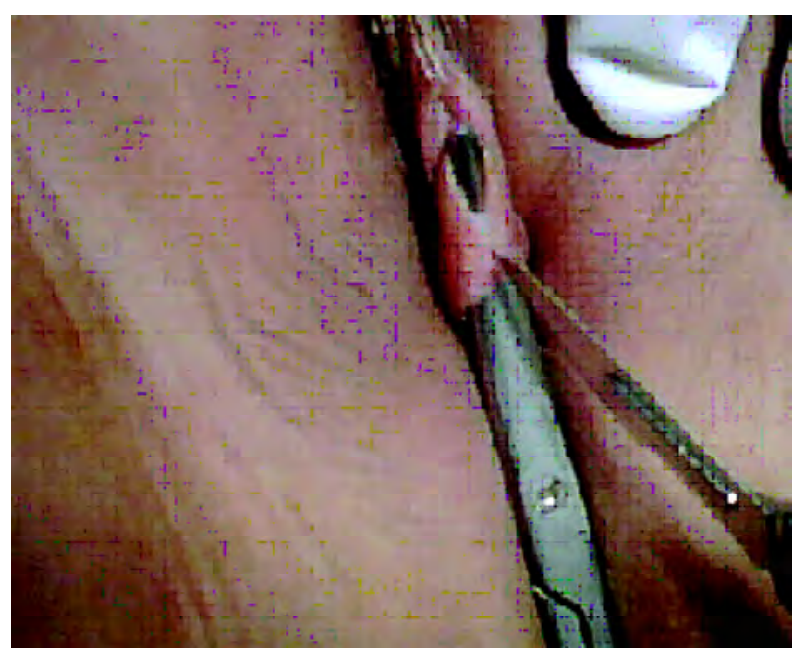

Figure 1. Recurrent labial adhesions just prior to separation.

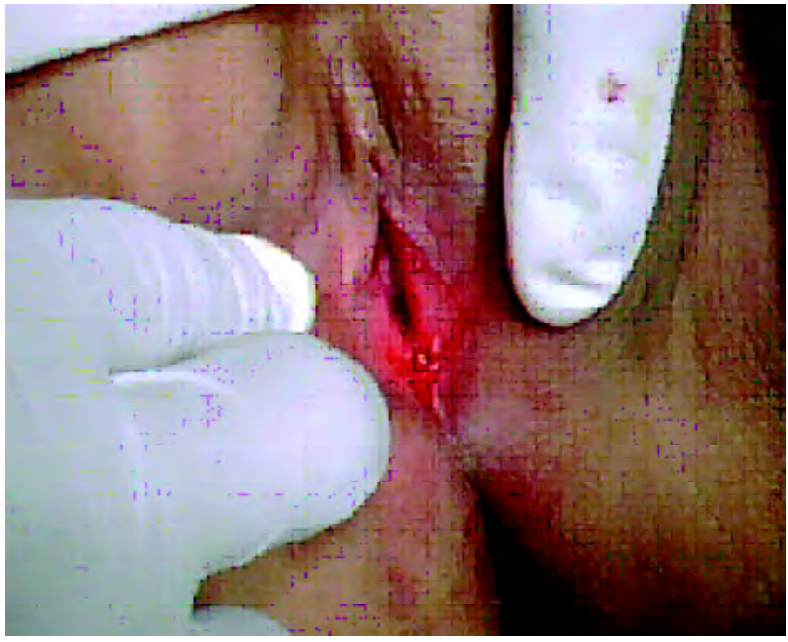

Figure 2. Separated labia with raw surface.

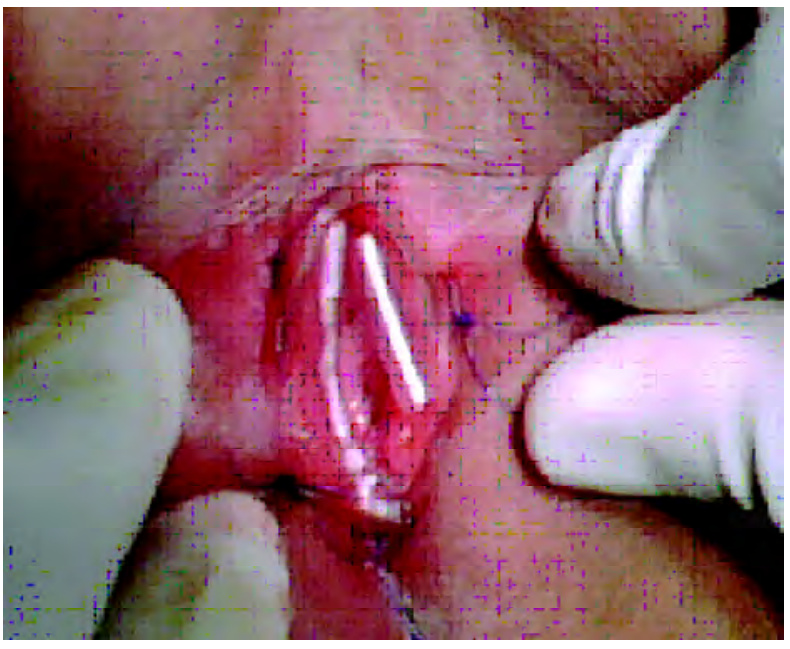

Figure 3. Sutured cut saline infusion tube pieces to the labia minora.

\section{Surgical technique}

Surgery was performed under general anaesthesia. During surgery labial fusion was separated by sharp dissection (Figure 2). Saline infusion tube cut to the length

${ }^{1}$ Department of Obstetrics and Gynaecology, University of Sri Jayewardenepura, ${ }^{2}$ Colombo South Teaching Hospital, Sri Lanka.

Correspondence: AKPR, e-mail: <akpmfc@gmail.com>. Received 30 March and revised version accepted 24 May 2012. Competing interests: none declared. 
of the raw area of the separated labial adhesions were sutured on to the edges using 3/0 polypropylene (Figure 3).

The tubes were removed on day 7. This effectively prevented contact of the raw surfaces until epithelialisation.

\section{Discussion}

Labial fusion is defined as partial or complete adherence of the labia minora or majora. The labia minora adhere together in the midline and translucent vertical line can usually be seen. The aetiology is not known but is associated with low oestrogen status [3]. However, labial fusion may be caused by infections, inflammatory conditions or dermatological conditions and local irritants.

Conservative management with local application of oestrogen is the first line of treatment [4]. When medical treatment failed and if condition is associated with urinary symptoms, surgical separation of adherent labia should be considered [5]. Usually this is carried out under general anaesthesia and the adhesions are divided by gentle traction or running a sound along the fusion line [6].

A recurrence rate of $11-14 \%$ has been reported after both modalities of treatment [7]. Adhesion of the raw area of the separated labia is considered a risk factor for recurrent adhesion. Recurring adhesions, especially when there has been prior surgical separation, are denser and therefore less likely to resolve with conservative management [6].

Use of saline infusion tube to prevent raw surfaces adhering together is used in ophthalmology practice in tarsorrhapy (to prevent eye lid adhesions). We tried using this technique to keep labia separated until denuded fibrosed area healed completely. During follow-up our patient did not have further recurrences.
Other surgical techniques like amniotic membrane and rotational skin flaps have been tried to prevent recurrent labial adhesions with varying success $[8,9]$.

\section{References}

1. Leung AK, Robson WL, Tay-Uyboco J. The incidence of labial fusion in children. Journal of Paediatrics and Child Health 1993; 29: 235-6.

2. Mayoglou L, Dulabon L, Martin-Alguacil N, Pfaff D, Schober J. Success of treatment modalities for labial fusion: a retrospective evaluation of topical and surgical treatments. Journal of Pediatric and Adolescent Gynecology 2009; 22: 247-50.

3. Schober J, Dulabon L, Martin-Alguacil N, Kow LM, Pfaff D. Significance of topical estrogens to labial fusion and vaginal introital integrity. Journal of Pediatric and Adolescent Gynecology 2006; 19: 337-9.

4. Leung AK, Robson WL, Kao CP, Liu EK, Fong JH. Treatment of labial fusion with topical estrogen therapy. Clinical Pediatrics 2005; 44: 245-7.

5. Muram D. Treatment of prepubertal girls with labial adhesions. Journal of Pediatric and Adolescent Gynecology 1999; 12: 67-70.

6. Michala S M. Fused labia: a paediatric approach. The Obstetrician and Gynaecologist 2009; 11:261-4.

7. Soyer T. Topical estrogen therapy in labial adhesions in children: therapeutic or prophylactic? Journal of Pediatric and Adolescent Gynecology 2007; 20: 241-4.

8. Lin YH, Hwang JL, Huang LW, Chou CT. Amniotic membrane grafting to treat refractory labial adhesions postpartum - a case report. The Journal of Reproductive Medicine 2002; 47: 235-7.

9. Johnson N, Lilford RJ, Sharpe D. A new surgical technique to treat refractory labial fusion in the elderly. American Journal of Obstetrics and Gynecology 1989; 161: 289-90. 